\title{
Study on the Horizontal Movement State of Suction Anchor Piles for Offshore Wind Power during Horizontal Pulling
}

\author{
Jianping Jiang, Jiaruo Gao \\ School of Marine Science and Engineering, Shanghai Maritime University, Shanghai, China \\ Email:jjpwx@163.com
}

How to cite this paper: Jiang, J.P. and Gao, J.R. (2022) Study on the Horizontal Movement State of Suction Anchor Piles for Offshore Wind Power during Horizontal Pulling. World Journal of Engineering and Technology, 10, 88-97.

https://doi.org/10.4236/wjet.2022.101005

Received: January 24, 2022

Accepted: February 22, 2022

Published: February 25, 2022

Copyright $\odot 2022$ by author(s) and Scientific Research Publishing Inc. This work is licensed under the Creative Commons Attribution International License (CC BY 4.0).

http://creativecommons.org/licenses/by/4.0/

\begin{abstract}
The subsea anchor piles of offshore wind power floating platform structures are mainly subjected to uplift and horizontal loads, and this paper focuses on the case of horizontal loads. A three-dimensional numerical simulation study of the horizontal pullout characteristics of wind power suction anchor piles in clay layers was carried out to reveal the horizontal movement state of the anchor piles during horizontal pile pullout, the range of pile depth at the pullout point where the horizontal movement is achieved (referred to as the horizontal movement range), the relationship between the pullout load and the ultimate load during the horizontal movement, and the optimal location of the pullout point for the horizontal movement. The results show that at certain pull-out points, the anchor pile produces an overall horizontal movement state under suitable horizontal pull-out loads. The depth of the pile pull-out point for horizontal movement is in the middle and lower part of the pile, i.e. $14.2 \mathrm{~m}$ to $14.5 \mathrm{~m}$. The horizontal pull-out load of $24,000 \mathrm{kN}$ at a depth of $14.5 \mathrm{~m}$ within the pile horizontal movement range of $14.2 \mathrm{~m}$ to 14.5 $\mathrm{m}$ is the maximum ultimate horizontal pull-out load; the optimum pull-out point depth is $14.5 \mathrm{~m}$ at $0.275 \mathrm{~L}$ ( $\mathrm{L}$ is the pile length). For each pull-out point of the anchor pile in horizontal movement, the horizontal pull-out load in horizontal movement and the horizontal ultimate pull-out load existed and it was found that the two values were not exactly the same, the values were compared and it was found that at the optimum pull-out point the value of the ultimate horizontal pull-out load/horizontal pull-out load in horizontal movement tended to 1 .
\end{abstract}

\section{Keywords}

Horizontal Movement State, Suction Anchor Piles, Horizontal Movement Range, Optimum Pull-Out Point Depth, Offshore Wind Power 


\section{Introduction}

Wind energy is a renewable and clean energy source, and compared to onshore wind energy, offshore wind energy has more obvious advantages [1] [2]. In shallow water depths of less than $50 \mathrm{~m}$, offshore wind power generation generally uses fixed foundation structures, i.e. pile foundations, gravity foundations and barrel foundations inserted directly into the seafloor strata.

With the gradual increase in national demand for offshore wind energy, the development of wind energy in shallow areas with water depths of less than $50 \mathrm{~m}$ will gradually become saturated; with offshore wind power going far out to sea and deep-sea areas is an inevitable trend.

At water depths of more than $50 \mathrm{~m}$, wind speed is stable and wind shear is low, which has the unique advantage of wind power generation. In this water depth, if a fixed foundation structure is used, the cost will increase significantly and is currently technically difficult to achieve. Therefore, in water depths of over $50 \mathrm{~m}$, wind power generation equipment needs to use floating foundations. Compared to fixed foundations, floating foundations have the advantages [3] of good mobility, easy dismantling and can be recycled at the end of their service life.

At present, there are three basic forms of wind power floating structures, namely the single column type (Spar), the semi-submersible type, and the tension leg type (TLP). The mooring system of wind power floating structures mainly consists of anchor chains and pile anchors, as shown in Figure 1(a). The anchor piles of offshore wind power floating platform structures are mainly subjected to uplift loads and horizontal loads [4], where the anchor piles of TLP platforms are mainly subjected to vertical uplift, while the anchor piles of SPAR platforms and semi-submersible platforms are mainly subjected to diagonal uplift and horizontal uplift (Figure 1(a)).

The pile anchor form of offshore wind power floating structure is divided into two types according to the construction method, one is the suction barrel foundation with negative pressure sinking technique, whose actual depth into the sea subsoil has exceeded $40 \mathrm{~m}$, and the other is the ordinary pile foundation with self-drilling and underwater hammering, whose actual depth into the sea subsoil has exceeded $130 \mathrm{~m}$. where the suction barrel is also called suction anchor, suction barrel pile, suction pile, which is referred to in this paper as seafloor suction anchor pile, or seafloor suction Anchor piles.

The suction anchor pile is a barrel-shaped thin-walled steel structure with an open bottom end and a closed top end with a pumping outlet [5] [6]. Compared to traditional pile foundations, suction anchor piles are less expensive, easier to transport and quicker to install on site, can be reused and can resist larger horizontal loads and bending moments. Therefore, suction anchor piles are very widely used in offshore wind power projects.

The research in this paper focuses on the case of seafloor suction anchor piles for floating platform structures subjected to horizontal loads. Some research 


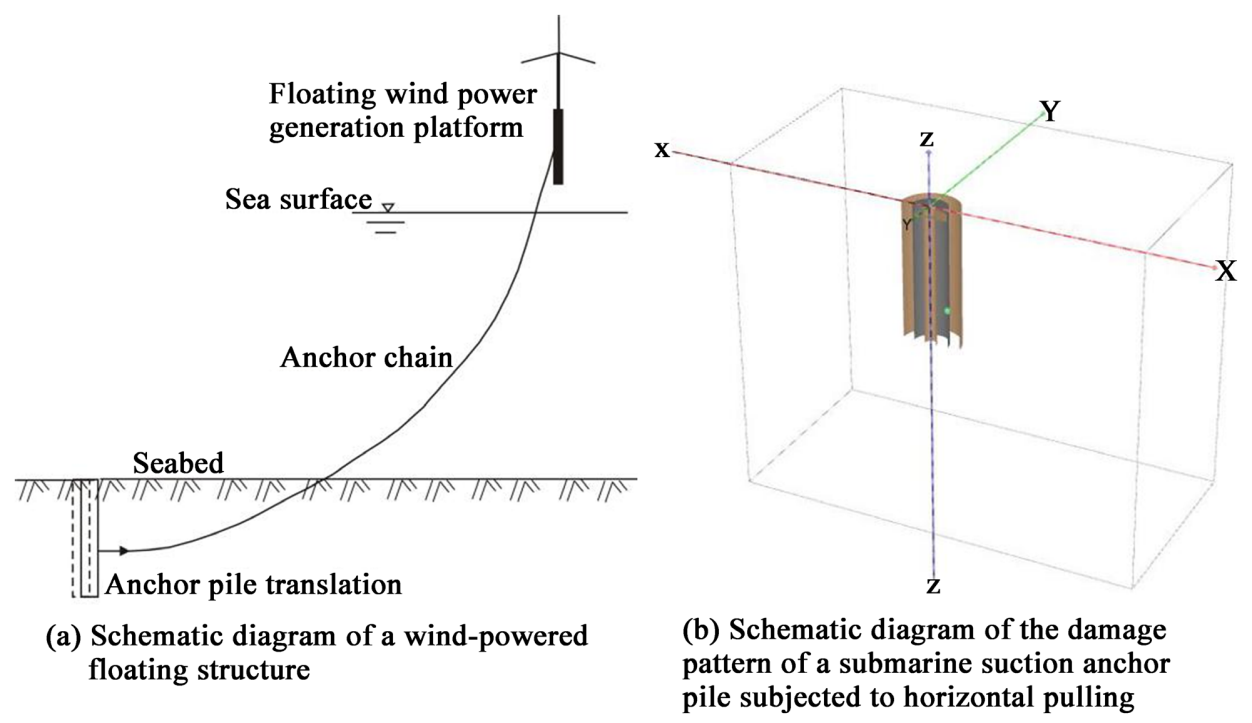

Figure 1. Diagram of horizontal movement and numerical model of a seafloor anchor pile for a wind turbine floating structure.

[7]-[14] has been carried out on the horizontal load behaviour of seafloor suction anchor piles.

Jin Shucheng et al. [9]. used a three-dimensional finite element model to analyse the destabilisation damage mechanism of suction barrel foundation when horizontal load is applied slowly, to explore the bearing performance of barrel foundation with different length-to-diameter ratios, to study the distribution of soil pressure on the external wall inside the barrel and the position of the rotation axis, and to derive the formula for calculating the horizontal ultimate bearing capacity of barrel foundation for saturated sand foundation according to the limit equilibrium solution method. Cui Yonggang [10] measured the ultimate bearing capacity of the corresponding pile under two situations of sandy soil and clay soil, combined with the soil parameters and barrel model specification parameters to give the ultimate horizontal bearing capacity calculation formula under the experimental environment, and then applied ABAQUS finite element analysis software to obtain the corresponding simulated horizontal bearing capacity. Based [11] on the three-dimensional finite element method, Liu Jinlong et al. analysed the horizontal bearing characteristics of the suction anchor pile foundation. [12] Based on the finite element model, Wang Peng et al. studied the influence of mooring point location, direction and anchorage depth on the bearing capacity of anchor piles.

The horizontal loads in the above studies are applied to the top of the pile of the subsea suction anchor pile; less research has been conducted on subsea suction anchor piles where the horizontal loads are applied to the pile body. The horizontal load in this study is applied to the pile body. There are three damage modes for seafloor suction anchor piles with horizontal loads applied to the pile body. The maximum ultimate pullout force is generally the case when the anchor pile is translating (Figure 1(a)) [11], and the translating state is one of the 
most important states and is well worth studying. However, no studies specifically addressing the horizontal movement state of anchor piles have been found. In view of this, this paper investigates the horizontal movement state of a suction anchor pile when the pile is subjected to horizontal pullout, the range of pile depth at the pullout point where the horizontal movement is achieved, the relationship between the pullout load and the ultimate load during horizontal movement, and the optimum location of the pullout point for horizontal movement.

\section{Numerical Model and Parameters}

The large international general geotechnical finite element software Plaxis 3D was used to carry out the 3D numerical simulation and the axisymmetric model was used in the numerical simulation, i.e. only half of the model was built. The computational domain model is $50 \mathrm{~m}$ high, $60 \mathrm{~m}$ long and $30 \mathrm{~m}$ wide. $5 \mathrm{~m}$ diameter and $20 \mathrm{~m}$ long suction anchor piles are used in the rigid body model. The Mohr-Coulomb model is used for the soil principal model.

The research in this paper concentrates on the pile horizontal movement state, optimum horizontal pull-out position, ultimate load, etc. To reduce the influencing factors, the seafloor foundation soil layer is set as a homogeneous clay layer. In fact, there are more [15] studies on the bearing properties of suction anchor piles carried out in submarine clay layers.

The parameters of the submarine clay layer are: modulus of elasticity $\mathrm{E}=6 \mathrm{e} 4$ $\mathrm{kN} / \mathrm{m}^{2}$, Poisson's ratio $v=0.31$ and $\gamma=19 \mathrm{kN} / \mathrm{m}^{3}$. The $3 \mathrm{D}$ numerical model established is shown in Figure 1(b), and the small green dots on the figure are the locations of the horizontal pull-out points.

\section{Numerical Simulation Results and Analysis}

\subsection{Horizontal Movement State of the Pile during Horizontal Pulling}

In the numerical simulation, the pulling points are set at different locations throughout the pile from top to bottom for horizontal pulling. At each point, the pulling load was increased from small to large and the load size was fine-tuned up and down at any time. The numerical simulation results showed that there were some pulling points where the whole suction anchor pile was produced in a state of overall horizontal movement during the horizontal pulling process. Considering the space, only the cloud diagram of the horizontal movement state of the pull-out point at $14.5 \mathrm{~m}$ depth and the cloud diagram of the front and rear inclination of the anchor pile, etc. are shown here, as shown in Figures 2-4.

A schematic diagram of the anchor pile in a horizontal movement state and tilted back and forth is shown in Figure 5 and is illustrated as follows.

1) Within the depth range of $0 \mathrm{~m}-14.1 \mathrm{~m}$ of the anchor pile, there is no horizontal movement of the anchor pile under any horizontal pulling load Fx, it is all forward inclined.

2) At a depth of $14.2 \mathrm{~m}$ in the pile, the anchor pile as a whole is translating 


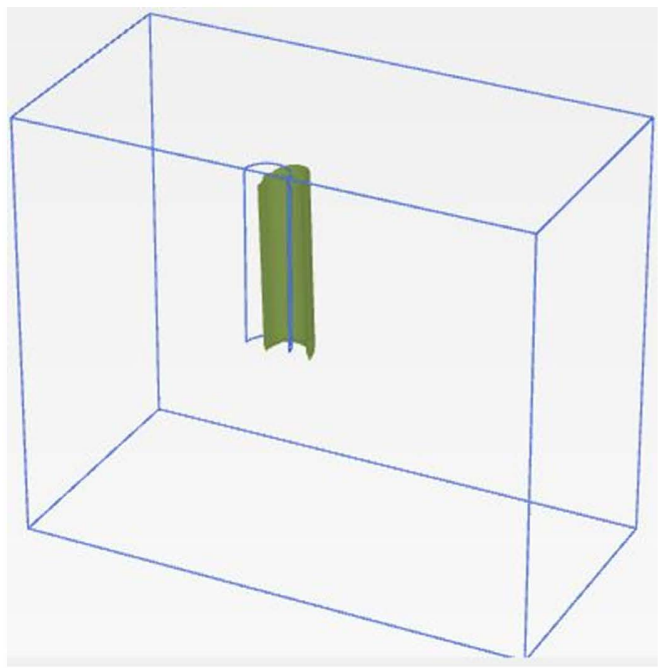

(a) Anchor pile setback diagram (magnified 10 times)

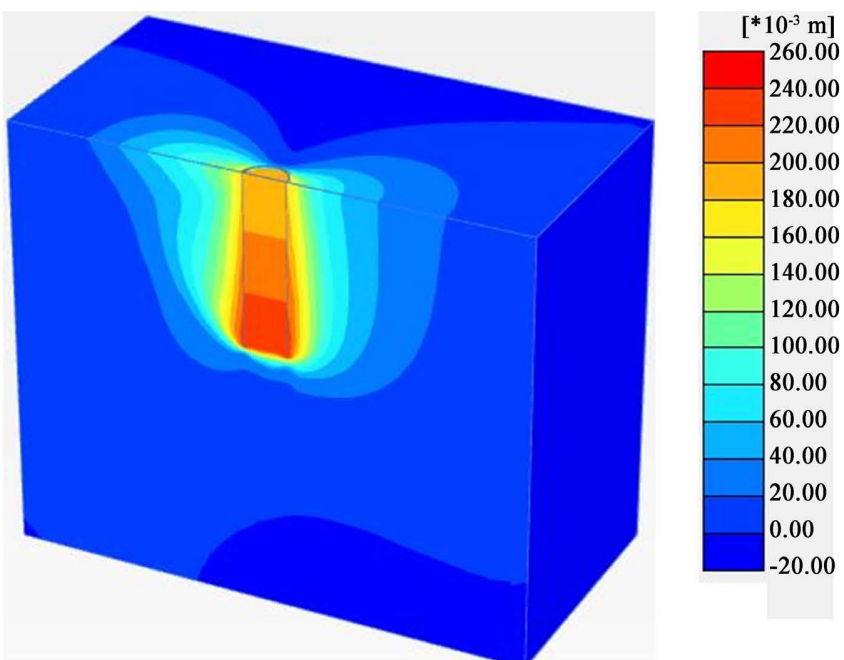

(b) Horizontal displacement cloud during backward tilt

Figure 2. The backward tilts of anchor pile when the horizontal pullout load $\mathrm{Fx}<27,510 \mathrm{kN}$ at $14.5 \mathrm{~m}$.

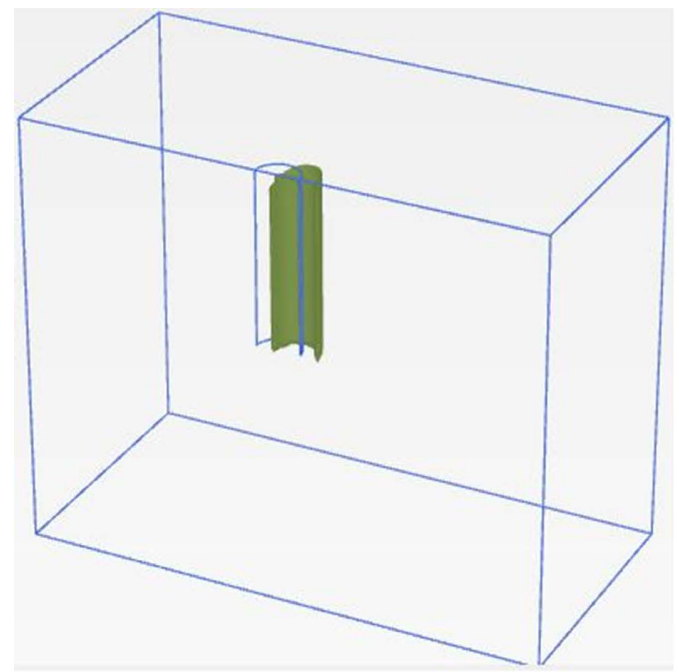

(a) Anchor pile horizontal movement plan $(5 \times$ magnification $)$

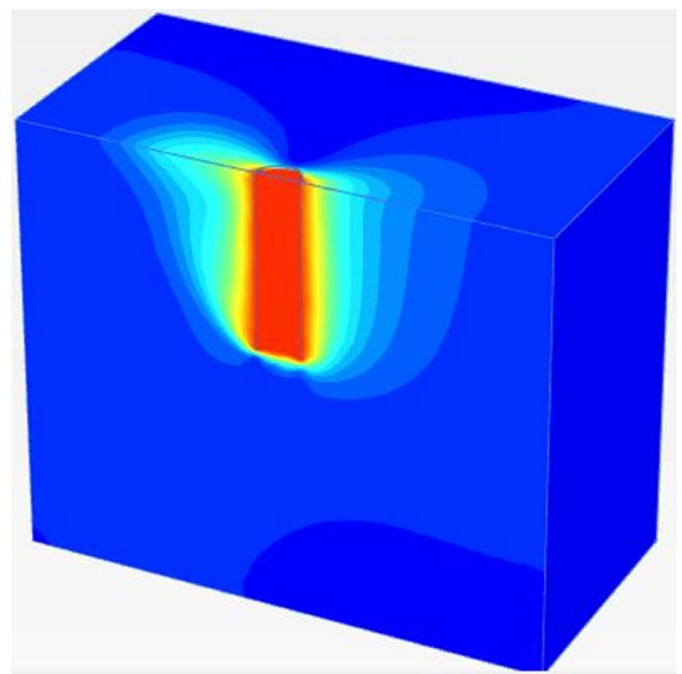

(b) Horizontal displacement clouds during horizontal movement

Figure 3. The horizontal movement of anchor pile when horizontal pullout load $\mathrm{Fx}=27,510 \mathrm{kN}$ at $14.5 \mathrm{~m}$.

when the horizontal pulling load $\mathrm{Fx}$ is equal to $17,950 \mathrm{kN}$, and tilting back when the horizontal pulling load is less than $17,950 \mathrm{kN}$, and tilting forward when it is greater than $17,950 \mathrm{kN}$. It was also found that all between $17,950 \mathrm{kN}$ and 5000 $\mathrm{kN}$ were horizontal movement, and less than $5000 \mathrm{kN}$ were also almost horizontal movement with a slight forward dip.

3) At a depth of $14.5 \mathrm{~m}$, the anchor pile is shifted horizontally when the horizontal pulling load $\mathrm{Fx}$ is equal to $24,000 \mathrm{kN}$, and is tilted back when the horizontal pulling load is less than $24,000 \mathrm{kN}$, and is tilted forward when it is greater than $24,000 \mathrm{kN}$.

4) Within the depth range of $14.6 \mathrm{~m}-20.0 \mathrm{~m}$ of the pile body, there is no horizontal movement of the anchor pile under any horizontal pulling load Fx, it is 


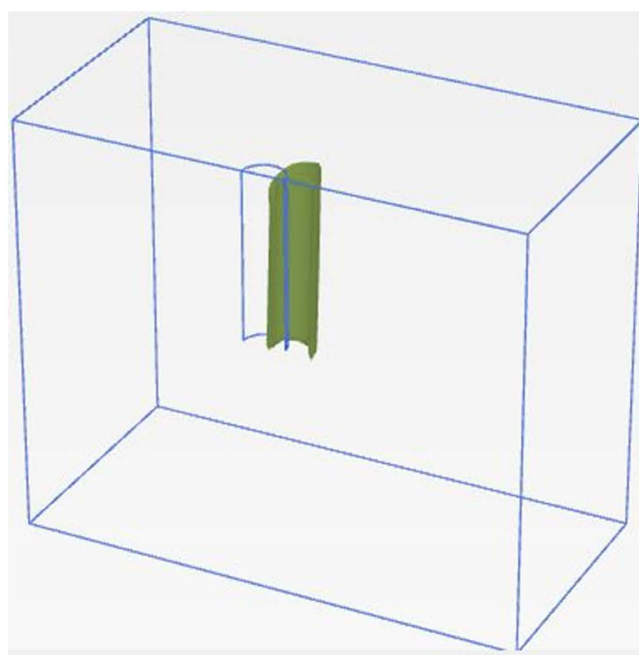

(a) Forward tilt diagram (magnified $5 \times$ )
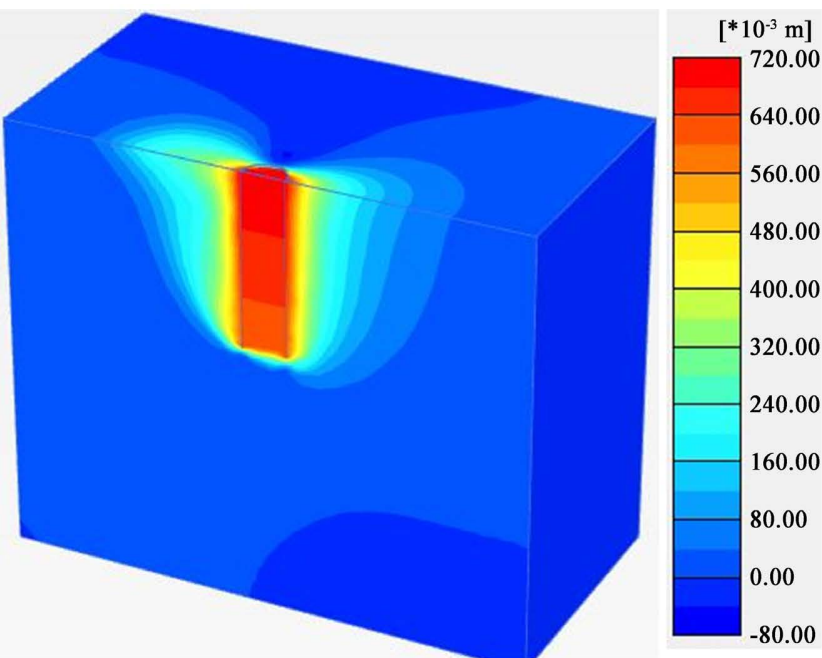

(b) Horizontal displacement cloud during forward tilt

Figure 4. The forward tilts of anchor pile when the horizontal pullout load $\mathrm{Fx}>27,510 \mathrm{kN}$ at $14.5 \mathrm{~m}$.

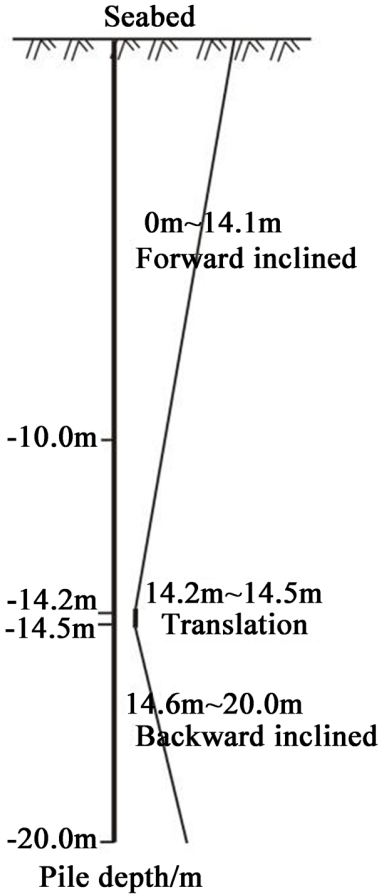

(a) horizontal movement and tilt over the entire depth

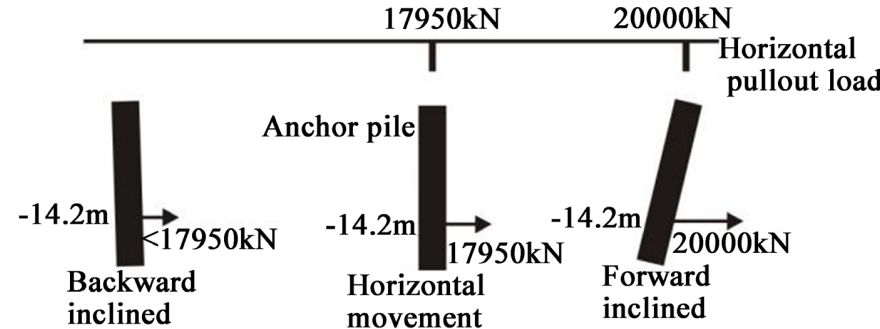

(b) the horizontal movement and tilt at $-14.2 \mathrm{~m}$

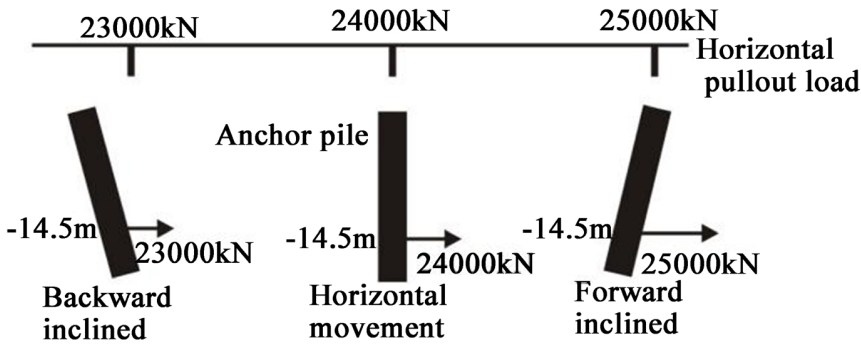

(c) the horizontal movement and tilt at $-14.5 \mathrm{~m}$

Figure 5. Schematic diagram of the anchor pile in horizontal movement and inclination.

all backward inclined.

\subsection{Horizontal Movement Range and Optimum Drawing Position}

It is known from the previous section that at certain pull-out points, under suitable horizontal pull-out loads, the anchor pile produces horizontal movement. The depth range of the pile pullout point where the horizontal movement state exists is referred to as the horizontal movement range. It is found that the anc- 
hor pile horizontal movement range is $14.2 \mathrm{~m}$ to $14.5 \mathrm{~m}$, as shown in Figure $5(a)$.

The horizontal pullout load-horizontal displacement curves of the representative pullout points of the whole pile body within the depth of $0 \mathrm{~m}-20 \mathrm{~m}$ on the pile body (5 pullout points at depths of $0 \mathrm{~m}, 5 \mathrm{~m}, 10 \mathrm{~m}, 14.5 \mathrm{~m}$ and $20 \mathrm{~m}$ ) are shown in Figure 6(a). The horizontal pullout load-horizontal displacement curves for the two pullout points of $14.2 \mathrm{~m}$ and $14.5 \mathrm{~m}$ within the horizontal movement range and the two pullout points of $14 \mathrm{~m}$ and15 $\mathrm{m}$ outside the horizontal movement range are shown in Figure 6(b). From Figure 6(a) and Figure $6(\mathrm{~b})$, it is found that the load-displacement curve of each pull-out point starts with a gentle growth, then rises steeply and there is an abrupt turning point, and the horizontal pull-out displacement at the turning point is between $50 \mathrm{~mm}$ and $200 \mathrm{~mm}$.

It is also found from the diagram that the location of the pull-out point has a great influence on the ultimate load carrying capacity of the suction anchor. $0 \mathrm{~m}$ to $20 \mathrm{~m}$ depth range, the pull-out load carrying capacity of each different depth pull-out point increases with depth, reaching the maximum pull-out load at 14.5 $\mathrm{m}$ depth, then the pull-out load becomes smaller with increasing depth. This is more clearly seen from the horizontal ultimate pullout load-depth curve in Figure 7. The pull-out point at a depth of $14.5 \mathrm{~m}$ is therefore referred to as the optimum pull-out point and is located at $0.275 \mathrm{~L}$ ( $\mathrm{L}$ is the pile length).

For each pull-out point of the anchor pile in horizontal movement, there exists a horizontal pull-out load in horizontal movement and a horizontal ultimate pull-out load, and it was found that the two values do not exactly coincide, and the two values were compared, as shown in Table 1 , and it was found that the value of the ultimate horizontal pull-out load/horizontal pull-out load in horizontal movement tends to 1 at the optimum pull-out point.

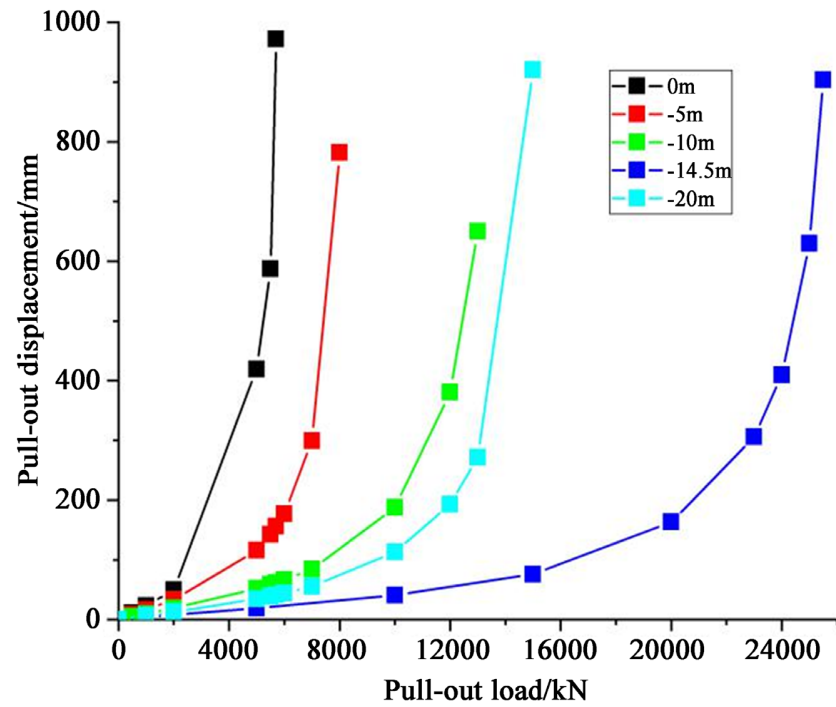

(a) Curves for each pull-out point of the full pile

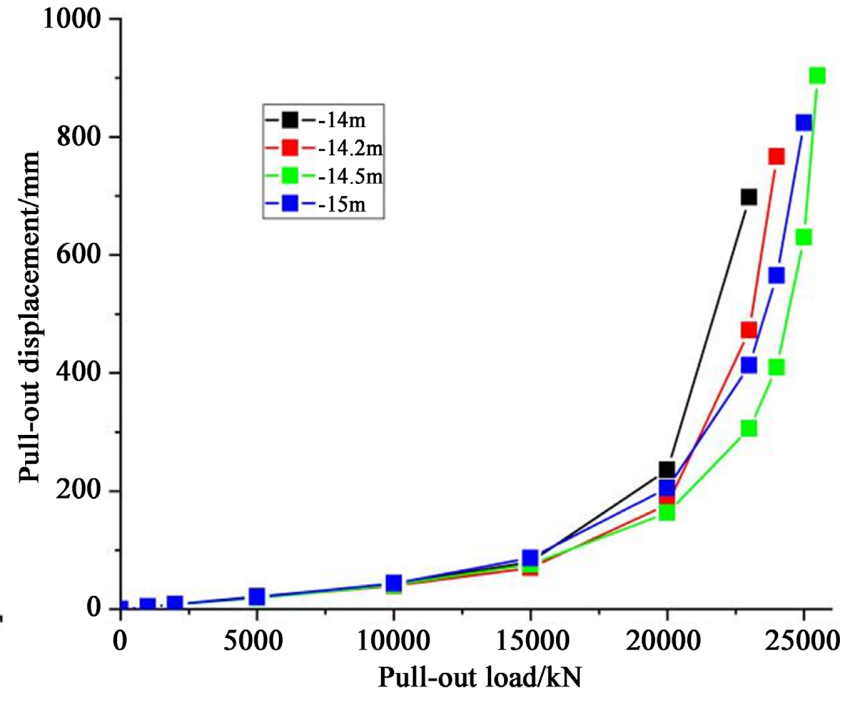

(b) Curves existing horizontal movement

Figure 6. Comparison of load-displacement curves at the horizontal pull-out point of the anchor pile. 


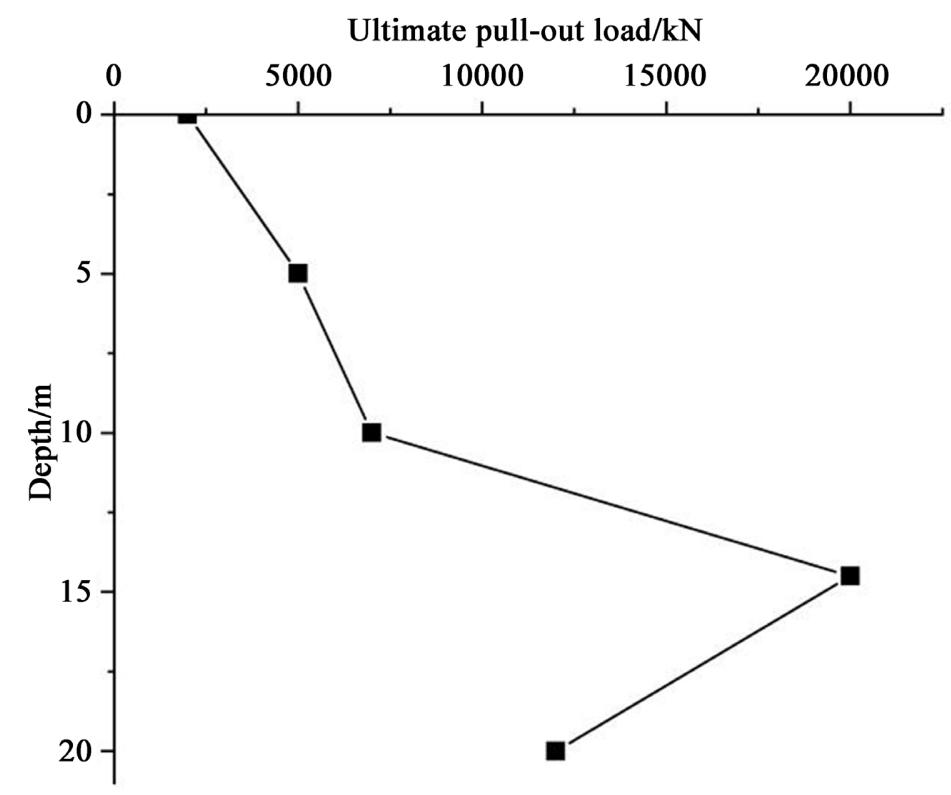

Figure 7. Horizontal ultimate load-depth curve at pile pull-out point.

Table 1. Comparison of horizontal pull-out loads with horizontal ultimate pull-out loads during horizontal movement.

\begin{tabular}{cccc}
\hline $\begin{array}{c}\text { Location } \\
\text { of pull-out } \\
\text { points }\end{array}$ & $\begin{array}{c}\text { Horizontal pull-out } \\
\text { load during horizontal } \\
\text { movement/kN }\end{array}$ & $\begin{array}{c}\text { Ultimate } \\
\text { horizontal } \\
\text { pull-out load/kN }\end{array}$ & $\begin{array}{c}\text { Ultimate horizontal pull-out } \\
\text { load/horizontal pull-out load } \\
\text { in horizontal movement }\end{array}$ \\
\hline $14.2 \mathrm{~m}$ & $17,950 \mathrm{kN}$ & 20,000 & 1.114 \\
$14.5 \mathrm{~m}$ & $24,000 \mathrm{kN}$ & 23,000 & 0.958 \\
\hline
\end{tabular}

\section{Conclusions}

Based on three-dimensional numerical simulations, the following conclusions were obtained by carrying out the horizontal movement state of the anchor pile during the horizontal pile pulling process of wind power suction anchor piles in clay layers, the range of pile depth at the pulling point where the horizontal movement is reached, the relationship between the pulling load and the ultimate load during the horizontal movement, and the optimal location of the pulling point for the horizontal movement.

1) At certain pull-out points, under suitable horizontal pull-out loads, the anchor pile produces a state of overall translation. The depth range of the pile pull-out points where the translational state exists is referred to as the translational range in the middle and lower part of the pile.

2) The load-displacement curve at each pull-out point of the pile body starts with a gentle increase and then rises steeply, with an abrupt turning point.

3) Within the depth range of $0 \mathrm{~m}-20 \mathrm{~m}$, the position of the pull-out point has a great influence on the ultimate horizontal pull-out force of the suction anchor pile. The pull-out load at each location increases with depth and reaches a maximum at a certain depth, then the horizontal pull-out load becomes smaller with 
increasing depth, and the best pull-out depth is at $0.725 \mathrm{~L}$ ( $\mathrm{L}$ is the pile length).

4) For each pull-out point of the anchor pile during horizontal movement, there exists a horizontal pull-out load during horizontal movement and a horizontal ultimate pull-out load, and it was found that the two values do not exactly coincide, and comparing the two values, it was found that the value of the ultimate horizontal pull-out load/horizontal pull-out load during horizontal movement tends to 1 at the optimum pull-out point.

5) This thesis is a study of horizontal pulling in cohesive seafloor soil conditions only. The horizontal movement state for sandy soils, multi-layered soils and inclined pulling situations will be studied in a separate paper.

\section{Acknowledgements}

This paper was supported by National Key Research and Development Program of China (2020YFE0201200).

\section{Conflicts of Interest}

The authors declare no conflicts of interest regarding the publication of this paper.

\section{References}

[1] Gelagoti, F., Georgiou, I., Kourkoulis, R. and Gazetas, G. (2018) Nonlinear Lateral Stiffness and Bearing Capacity of Suction Caissons for Offshore Wind-Turbines. Ocean Engineering, 170, 445-465. https://doi.org/10.1016/j.oceaneng.2018.10.020

[2] Yang, X., et al. (2018) Lateral-Moment Loading Capacity and Bearing Behavior of Suction Bucket Foundations for Offshore Wind Turbines in Sand. International Journal of Geomechanics, 18, 44-49. https://doi.org/10.1061/(ASCE)GM.1943-5622.0001279

[3] Tang, Y.G., Qu, X.Q., Li, Y., et al. (2021) Dynamic Response Characteristics of TLP Type Offshore Floating Wind Turbine in Freak Wave. The Ocean Engineering, 39, 1-11.

[4] Jiang, J.P. and Chen, W.J. (2016) Calculation Method of Partially Embedded Single Pile under Complex Horizontal Load. Water Transport Engineering, No. 7, 116-121.

[5] Li, S.-Z., Wang, Z.-C., Jia, X., et al. (2019) Simplified Calculation Method for Cyclic Bearing Capacity of Suction Anchors with Taut Mooring in Soft Clay. Rock and Soil Mechanics, 40, 1704-1712.

[6] Luo, L.B., Wang, Y., Huang, J.Q., et al. (2021) Research on the Influence of Ocean Cyclic Load on the Horizontal Bearing Capacity of Suction Bucket Foundation. Acta Energiae Solaris Sinica, 42, 142-147.

[7] Li, D.Y., Zhang, Y.K., et al. (2015) Capacity of Modified Suction Caissons in Marine Sand under Static Horizontal Loading. Ocean Engineering, 102, 1-16. https://doi.org/10.1016/j.oceaneng.2015.04.033

[8] Kim, S., Choo, Y.W., et al. (2016) Pullout Capacity of Horizontally Loaded Suction Anchor Installed in Silty Sand. Marine Georesources and Geotechnology, 34, 87-95. https://doi.org/10.1080/1064119X.2014.961622

[9] Jin, S.C., Zhang, Y.T., Yang, Y.H., et al. (2013) Research on Horizontal Bearing Capacity of Suction Bucket Foundation in Saturated Sand Ground. Rock and Soil Me- 
chanics, 34, 221-227. https://doi.org/10.1061/9780784413425.025

[10] Cui, Y.G. (2016) Research on Horizontal Bearing Capacity of Bucket Foundation. Master Thesis, Tianjin University, Tianjin, 12.

[11] Liu, J.L., Chen, L.W., Wang, J., et al. (2016) Characteristics of Horizontal Bearing Capacity of Suction Anchor Foundation in Ocean Engineering. Journal of Civil Engineering and Management, 33, 1-5.

[12] Wang, P., Wang, X.T. and Zhang, X.F. (2019) Finite Element Analysis of Bearing Characteristics of Deep-Water Suction Anchor Foundation in Clay. Construction Technology, 48, 24-28.

[13] Bang, S., Leahy, J.C., Cho, Y., et al. (2006) Horizontal Bearing Capacity of Suction Piles in Sand. Transportation Research Record, 108, 21-27. https://doi.org/10.1177/0361198106197500103

[14] Zhou, X.H., Wang, Y.H. and Deng, R. (2020) Summary of Floating Infrastructure Structure of Offshore Wind Turbine. China Power, 53, 100-106.

[15] Aubeny, C. and Murff, J.D. (2005) Simplified Limit Solutions for the Capacity of Suction Anchors under Undrained Conditions. Ocean Engineering, 32, 864-877. https://doi.org/10.1016/j.oceaneng.2004.10.006 